\title{
Deaths from cirrhosis in Poland and Hungary: the impact of different alcohol policies during the 1980s
}

\author{
Zsuzsa Varvasovsky, Chris Bain, Martin McKee
}

\begin{abstract}
Objective - To compare patterns of deaths from cirrhosis in Poland and Hungary in the context of differing alcohol policies in the $1980 \mathrm{~s}$.

Design - Cohort analysis of deaths from chronic liver disease and cirrhosis between 1959 and 1992 using mortality data from the World Health Organization database. Results - The pattern of alcohol related mortality in these countries is quite different. In both countries, death rates increased in the 1960 s and 1970s. In Poland, this increase was arrested in 1980 and death rates have levelled out, with the exception of those in young females. In Hungary, rates have continued to climb, although the rate of increase decreased in the 1980s. This change coincides with the introduction of a policy, following the introduction of martial law, to reduce alcohol consumption.

Conclusions - The countries of central and eastern Europe display many similarities in both political history and measures of health such as overall life expectancy. When examined more closely, substantial differences emerge. Policy makers must be cautious about adopting global solutions to health challenges that fail to take into account national variations.
\end{abstract}

(F Epidemiol Community Health 1997;51:167-171)

European Centre for Health of Societies in Transition

(ECOHOST), London School of Hygiene and Tropical Medicine, Keppel Street, London WC1E 7HT Z Varvasovsky M McKee

Department of Social Medicine, Medical University of Debrecen, Hungary Z Varvasovsky

Department of Social and Preventive Medicine, University of Queensland Medical School, Herston, Queensland 4006, Australia C Bain

Correspondence to: Professor M McKee. Accepted for publication September 1996
It is now apparent that levels of health in the former socialist countries of central and eastern Europe are substantially worse than those in the west. ${ }^{1}$ Despite rapid improvements in mortality in the period immediately after the second world war, by the mid 1960s the health of their populations began to stagnate. The subsequent steady improvement in the west has left them further and further behind so that now their life expectancy at birth is typically five to six years less than in the west. This phenomenon has stimulated a growing body of research, summarised recently by Bobak and Marmot. ${ }^{2}$ In brief, the groups most affected in these countries are men, especially those in early middle age and who are unmarried, ${ }^{3}$ and the greatest increases among causes of death are those from chronic diseases and, especially, ischaemic heart disease and cancer. As adult health has deteriorated, infant mortality has improved, so that global measures such as life expectancy at birth conceal a rather complex pattern.
Most authors, in seeking to explain this phenomenon, have directed their attention to the substantial differences between the two parts of Europe and have paid rather less attention to the existence of heterogeneity within central and eastern Europe. This seems rather surprising as, in western Europe, it is widely recognised that there are very large variations in death rates from, for example, ischaemic heart disease and many forms of cancer. ${ }^{4}$ One study that examined the contribution of different causes of death to changing life expectancy in three central European countries during the 1980s showed substantial national differences. Most notably, in Hungary, where the decline in life expectancy has been especially large, alcohol related deaths had a very much greater impact than in Poland or Czechoslovakia. ${ }^{5}$ This study seeks to develop this observation further. It examines the apparent difference in alcohol related mortality between Hungary and Poland, two countries with, superficially, broadly similar experiences in the post war era. It employs cohort analysis to ask whether this apparent difference is real, whether there are any factors that could account for it, and whether any period, age, or cohort effect could be observed.

\section{Methods}

Data from the World Health Organization mortality tapes from 1959 to the present were analysed. These contain data in five year age bands (one year for the under $5 \mathrm{~s}$ ) broken down in relation to sex and cause of death using the abbreviated mortality codes. Over this period four different editions of the International Classification of Diseases (ICD) were used. Deaths categorised as cirrhosis of the liver or chronic liver disease and cirrhosis were studied as the categories within the abbreviated codes most closely linked to alcohol consumption. The codes used in each edition of the ICD are shown in table 1 .

As these data span three editions of the ICD it is important to consider whether this could have any effect on the trends observed. There was no consistent discontinuity in death rates coinciding with changes in ICD editions, al-

Table 1 International Classification of Diseases (ICD) codes used in the analysis

\begin{tabular}{lll}
\hline ICD edition & Label & Code \\
\hline 7th & Cirrhosis of the liver & $\mathrm{A} 105$ \\
8th & Cirrhosis of liver & $\mathrm{A} 102$ \\
9th & Chronic liver disease and cirrhosis & B347 \\
\hline
\end{tabular}




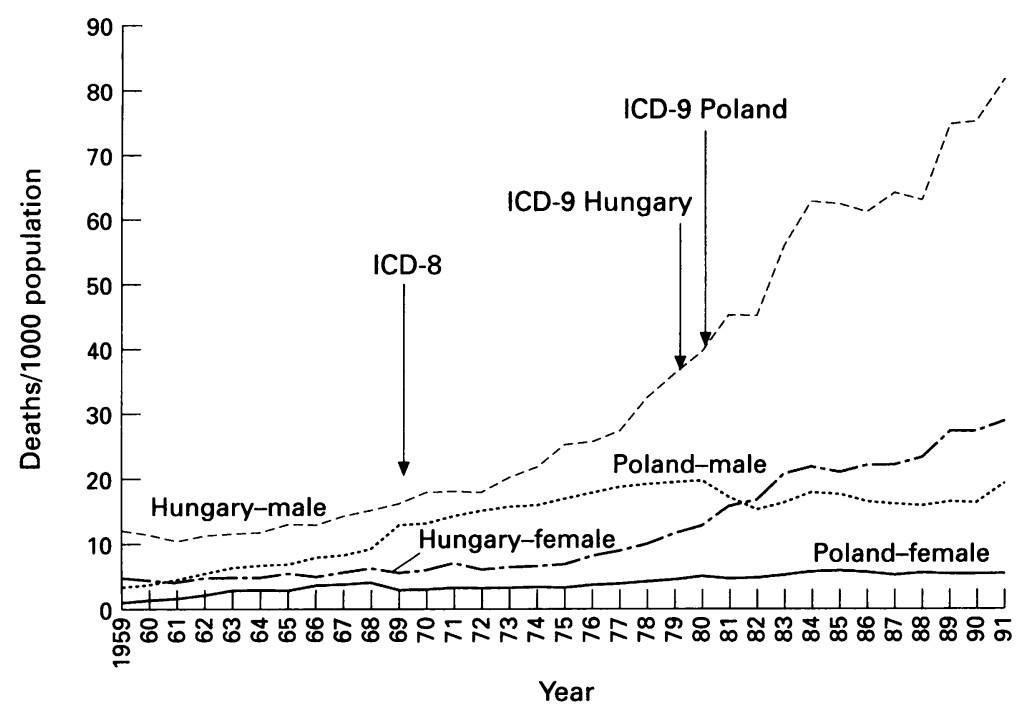

Figure 1 Crude death rates from chronic liver disease and cirrhosis - effect of a change in the edition of the International Classification of Diseases.

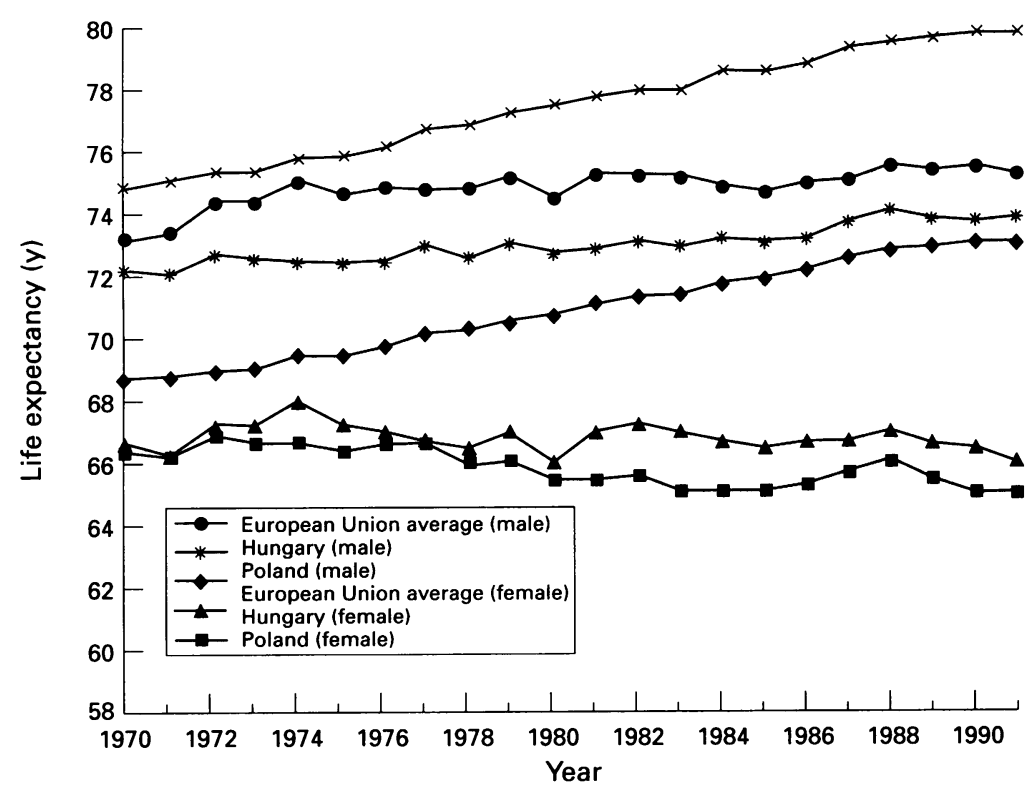

Figure 2 Life expectancy at birth in the European Union, Hungary and Poland between 1970 and 1991. selected years until 1970, life expectancy at birth was similar in Poland and Hungary during the 1960 s. In the early 1970 s the two countries began to diverge but, from the mid 1970s, the trends remained parallel and relatively constant until the present, with the figures for Poland typically being about 1.5 years longer than in Hungary. In contrast, life expectancy in western countries has steadily increased over this period, leaving Poland and Hungary increasingly far behind (fig 2).

While the trends in life expectancy suggest that the health situations in Poland and Hungary have been broadly similar since the 1970 s, this view is dispelled by a more detailed examination by cause of death. In the case of chronic liver disease and cirrhosis, the topic of this paper, there has been a dramatic increase in deaths in Hungary since the early 1970s but little change in Poland over this period.

Two sets of graphs have been drawn to illustrate changes over time. In the first, deaths have been aggregated into ten year age bands and, indexing the rate in the first period (195963) as 100 , show the change relative to the initial period in each subsequent five year period (figs 3 and 4). In the second set of graphs, age and sex specific death rates, in five year bands, were plotted by the central year of birth for those dying in each five year period from 1959-91 (except that the last period spans only three years from 1989 to 1991 because of non-availability of data). A semilogarithmic scale has been used, as is conventional in cohort analyses, to show the rate of change (figs 5 and 6). In both cases, because of the small numbers involved and to enhance clarity of the figures, data for those dying under 30 are not shown. To place the changes in context, figures for annual alcohol consumption between 1970-91, as reported in the World Health Organization's Health For All database are also presented (fig 7).

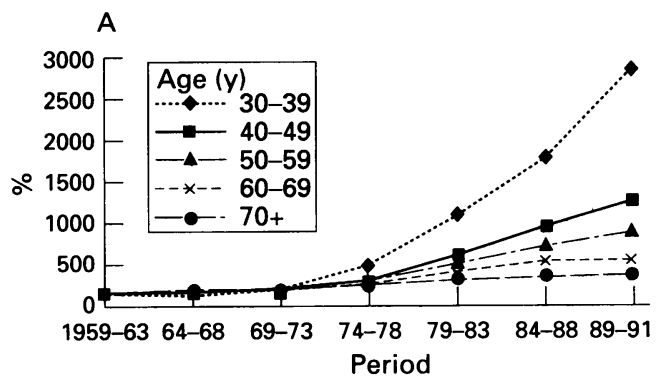

B

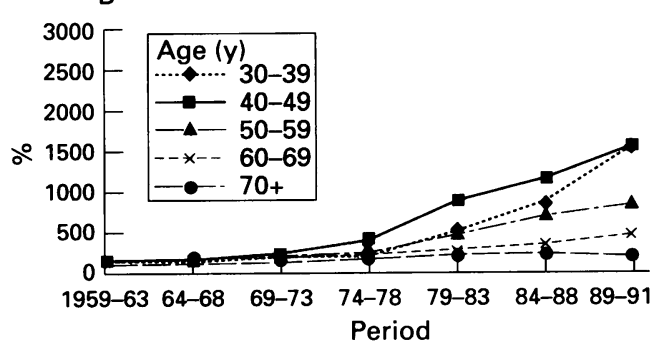

Figure 3 Changes in age specific death rates from chronic liver disease and cirrhosis among Hungarian men $(A)$ and women $(B)(1959-63=100)$. 
A
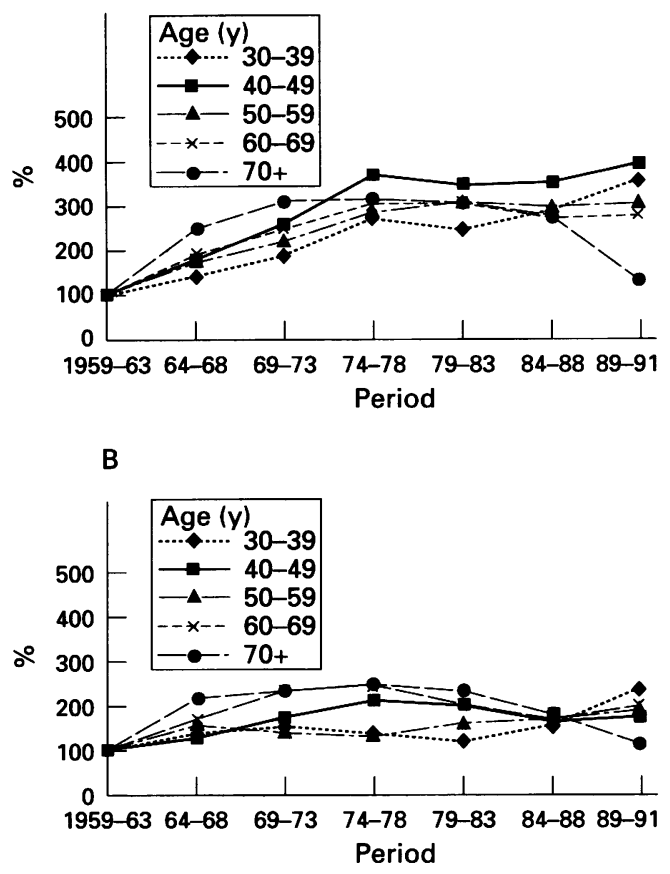

Figure 4 Changes in age specific death rates from chronic liver disease and cirrhosis among Polish men $(A)$ and women $(B)(1959-63=100)$.

Inspection of age specific death rates in each period of death reveals strikingly different patterns in the two countries. In both countries, and in all age groups, there have been increases in mortality but the magnitude of change is very much higher in Hungary, with an almost $3000 \%$ increase among men aged 30 to 34 . This increase is progressively less among older
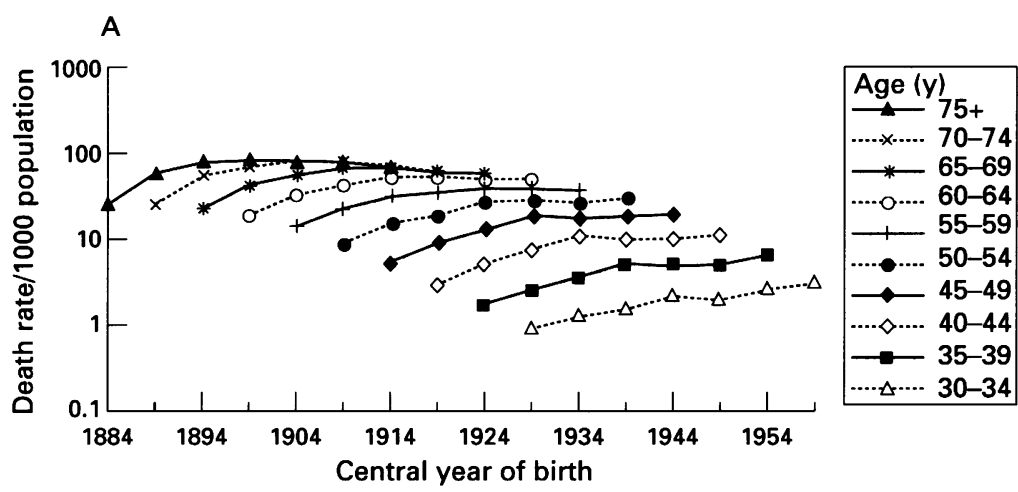

B

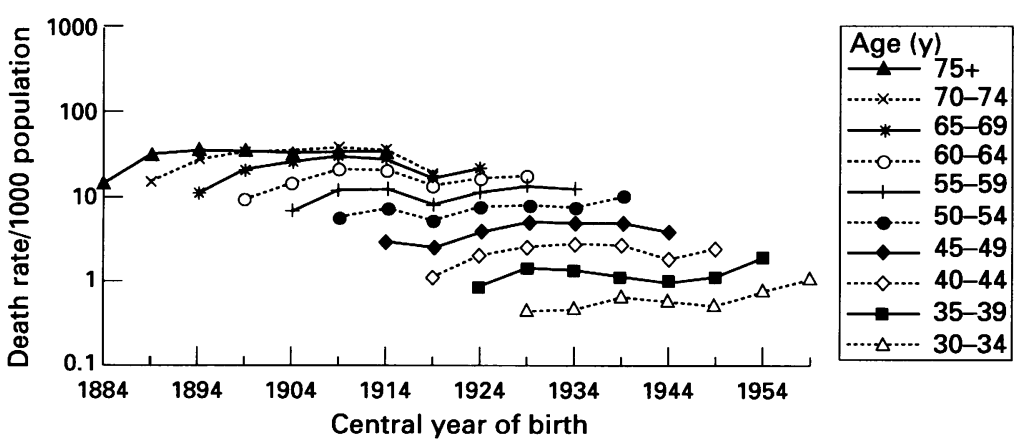

Figure 5 Age specific death rate from chronic liver disease and cirrhosis in relation to year of birth in Polish men $(A)$ and women $(B)$ for seven selected periods. age groups but, even for those aged 60-64 the increase has been over $500 \%$ (fig $3 \mathrm{~A}$ ). The increases have been somewhat less among Hungarian females but, even here, in the youngest age group it has been over $1500 \%$ (fig 3B). In contrast, among Poles, while death rates increased in the early part of the period under study, there has been little further increase since the early 1980s (fig 4).

The second set of graphs show differences in the rate of change over time in relation to year of birth. The extreme left hand point in each series represents deaths occurring in 1959-63 and the extreme right hand point represents deaths in 1989 to 1993. In Poland, male death rates increased for all age groups until about 1981 and subsequently levelled out, except for small increases among the young in the late 1980s (fig 5). The curves are almost parallel until the age group 55-59. Above this age, while the transition from an underlying upward trend still occurs around 1981, there is also an earlier slowing of the rate of increase. The lower numbers of female deaths introduces a greater element of instability but there is still a general upward trend in the earlier years of the study period, although an abrupt change around 1981 is less apparent (fig 5). The pattern in Hungary is markedly different. For both sexes, the rate of increase during the 1960 s (the left side of each data series) was similar to that seen in Poland. Thereafter, instead of levelling out as in Poland, the rate accelerated upwards (fig 6). The rate of increase has, however, slowed during the 1980s. As suggested earlier, the rates of increase have been greatest among the younger age groups.

\section{Discussion}

For diseases with a distribution heavily influenced by age, simple analysis of trends in mortality, even when age standardised, may be misleading. Age period cohort analysis can add substantially to understanding of underlying trends. ${ }^{7}$ In particular, it can help to differentiate cohort effects, in which changes in frequency of disease across the age groups of successive cohorts reflect the unique exposures of those cohorts; period effects, in which a common experience causes changes occurring across all age groups alive at a particular time; and age effects, in which changes in frequencies are related only to changes in age and not to either period or generation. For example, this approach was used by Susser in 1961 to challenge the then current view that the incidence of peptic ulcer was rising. ${ }^{8}$ The analyses contained in this paper similarly challenge widely held views about the pattern of alcohol related mortality in Poland and Hungary.

A few caveats are necessary. This study is limited both in terms of types of deaths studied and in the analysis undertaken. There are many other diseases that are linked aetiologically to alcohol. Although the category "chronic liver disease and cirrhosis" will include a spectrum of non-alcohol related diseases, these constitute only a small proportion of these deaths. According to some sources the percentage of 

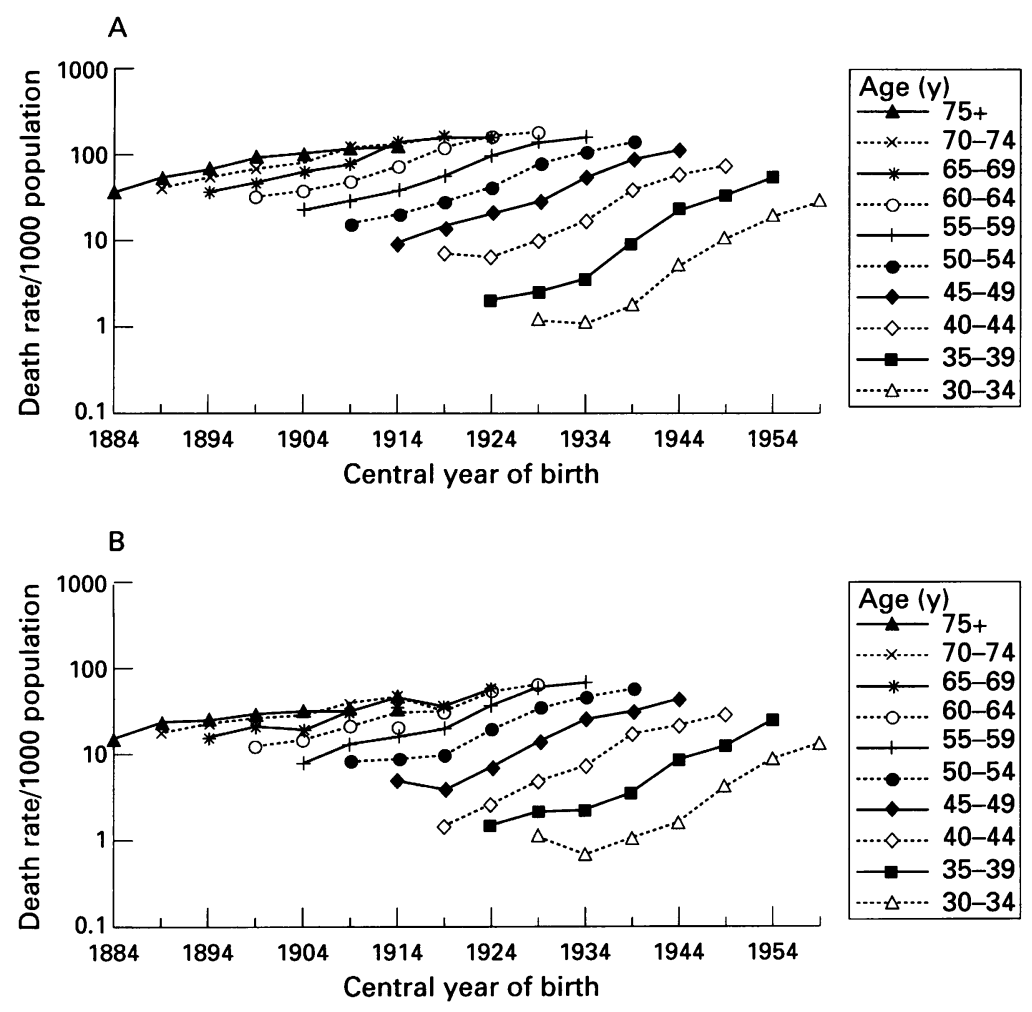

Figure 6 Age specific death rate from chronic liver disease and cirrhosis in relation to year of birth in Hungarian men $(A)$ and women (B) for seven selected periods between.

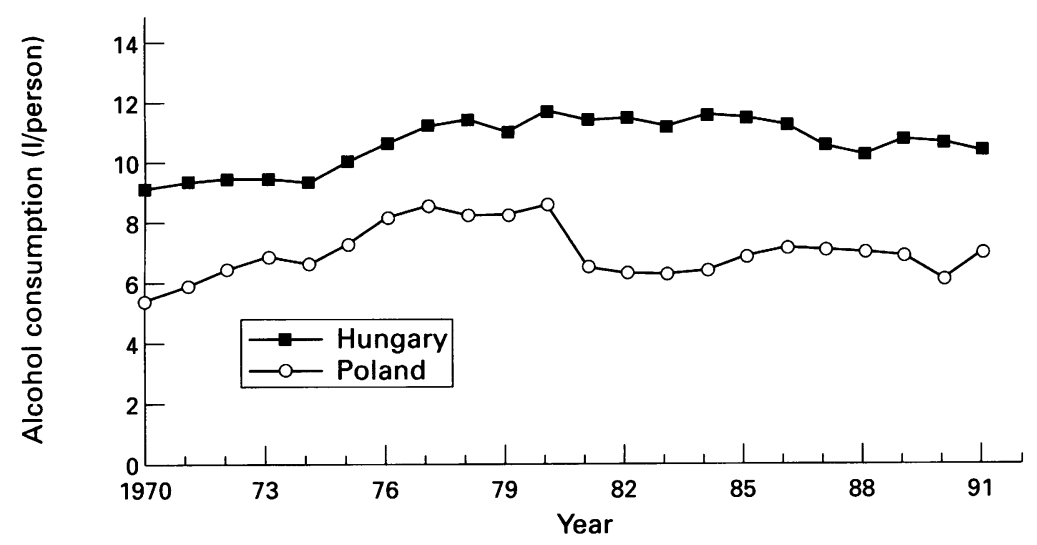

Figure 7 Consumption of pure alcohol in Hungary and Poland, 1970-91.

deaths attributable to alcohol in chronic liver disease and cirrhosis ranks from 66 to $100 \%$ making it possible to consider this cause of death as a relatively good marker of alcohol problems within a community. ${ }^{9}$ Furthermore, unlike the situation with alcohol where there is strong independent evidence of changes in exposure, we know of no similar evidence that would suggest that the other causes of liver disease have changed significantly. A pragmatic consideration was that data are only easily available throughout the study period in the form of the abbreviated mortality classification.

The analysis has been limited to visual examination of the various curves generated. It is recognised that some authors, when undertaking cohort analysis, have supplemented visual inspection with statistical modelling in an attempt to separate age and period effects. A more detailed critique of modelling is set out in a paper by Kupper who concludes that "such regression methods cannot be said to provide important interpretational advantages over graphical approaches". ${ }^{10}$

Despite many superficial similarities between these two countries, the patterns of deaths from chronic liver disease are quite different. This is an important cause of death, accounting for a reduction of over half a year in life expectancy at birth among Hungarian males between 1979 and $1990 .{ }^{5}$

Cohort analysis helps to demonstrate who is dying from this disease and how this has changed over time. In Hungary, alcohol continues to pose a substantial and increasing threat to health. Although the rate of increase in death rates has slowed, the trend is still upwards. All age groups over 30 are affected but the greatest increases have been among the young. In Poland, in contrast, despite a rising death rate before 1980 , this has now ceased, except among young women.

The greater importance of alcohol as a risk factor in Hungary than in Poland receives independent support from a report of recent trends in cancer of the oesophagus, for which alcohol is also an important risk factor. The age standardised death rate has increased much more steeply in Hungarian men than in their Polish counterparts and cohort analysis demonstrates a pattern similar to that reported here. ${ }^{11}$

The official statistics on alcohol consumption also support this view. Although such figures are notoriously unreliable because of, for example, illicit production, they can give some idea of trends. They show a steady rise in the volume of pure alcohol sold in both countries from 1970 but, unlike Hungary where it has continued to rise, there was a substantial fall in Poland after 1980 (fig 7). ${ }^{12}$ This coincides with the change in the rate of increase of cirrhosis mortality in Poland and can be considered as a period effect. Unfortunately, as these figures are based on aggregate consumption statistics, they give no idea of the pattern of drinking. In neither country are there adequate survey data covering this period.

It may seem surprising that the change in consumption in Poland could cause such as rapid cessation in the increase of deaths from cirrhosis given the long period over which cirrhosis develops. Such an effect has been described in other situations, such as that in Paris in 1942 when alcohol rationing was introduced due to shortages arising from the war. Alcohol consumption was estimated to have fallen by $80 \%$ in one year and deaths from cirrhosis fell by $50 \%$ in the same period. ${ }^{13}$ This has been explained as reflecting the reservoir of people with cirrhosis for whom short term changes in consumption may either hasten or delay death quite considerably. ${ }^{14}$

The circumstances surrounding this decrease have been described by Wald and Moskalewicz. ${ }^{15}$ In $1980-81$, Solidarity blamed the Polish government for promoting alcohol to hide the deeper problems of society and to obtain more revenue. Faced with this pressure, alcohol policy was tightened. Production decreased, temporary prohibition and rationing 
were imposed, and alcohol prices rose substantially. The policy was continued after the imposition of martial law and only slightly liberalised during the mid-1980s. ${ }^{16}$ In Hungary, no similar policy initiative was introduced during this period, although the problem was recognised. Several new bodies were established to tackle alcohol related problems and research was initiated but this activity focused on the management of those who already had clinically apparent problems. ${ }^{1718}$ Despite these measures, the availability of alcohol steadily increased ${ }^{19}$ during the 1980 s and their price lagged behind inflation. ${ }^{20}$ It was only at the end of the 1980 s, partly in response to the crackdown on alcohol in the Soviet Union, that access to alcohol became more restrictive, with laws limiting the sale of alcoholic beverages before $9 \mathrm{am}$, bans on the sale of alcohol around schools and health care facilities, and price increases. ${ }^{21}$ In practice, these Hungarian initiatives seem to have had little impact on alcohol consumption and consequent mortality.

This study provides further evidence of the complexity of the health challenges facing central and eastern Europe. From a distance, it is clear that the countries in this region have many similarities. In each of them, life expectancy increased in the immediate post war period but subsequently has either stagnated or, for men, fallen. This has been due to an increase in chronic diseases affecting, especially, those in early middle age and has been offset to some extent by improvements in infant mortality. As one looks closer, however, the differences emerge. Some, such as the high level of HIV/ AIDS and maternal mortality in Romania have received considerable attention. Others, such as the consequences of alcohol, are less well known.

The countries of central and eastern Europe may look similar from a distance but differences emerge on closer inspection. Much that has been written on this topic has focused on the gap between east and west. As the cases of death vary, so too should the policy responses.
Dr Varvasovszky is funded by the World Bank Hungarian Public Health programme.

1 Forster DP, Jozan P. Health in eastern Europe. Lancet 1990; 335:458-60.

2 Bobak M, Marmot $M$. East-west mortality divide and its potential explanations: proposed research agenda. $B M \mathcal{f}$ 1996;312:421-25.

3 Hajdu P, McKee M, Bojan F. Changes in premature mortality differentials by marital status in Hungary and in

4 Abel-Smith B, Figueras J, Holland W, McKee M, Mossialis E. Choices in health policy: An agenda for the European Union. Aldershott/Luxembourg: Dartmouth Press/Offic for Official Publications of the European Communities.

5 Chenet L, McKee M, Fulop N, Bojan F, Brand H, Hor A, Kalbarczyk P. Changing life expectancy in central Europe: is there a single reason? F Public Health Med 1996; 18:329-36.

6 Office of Population Censuses and Surveys: Mortality statistics. Comparison of the 8th and the 9th revision of the International Classification of Diseases; Series DH1, No 10 , London: OPCS, 1983.

7 Esteve J, Benhamou E, Raymond L. Statistical methods in cancer research, Vol IV. Descriptive epidemiology. Lyons: IARC, 1994.

8 Susser MW. Environmental factors and peptic ulcer. Practitioner 1961;186:302-11.

9 Maynard A, Godfrey C. A health strategy for alcohol: setting targets and choosing policies. Occasional Paper 1. Leeds Center for Health Economics/Leeds Addiction Unit, May 1992, Appendix 1

10 Kupper L, Janis JM, Karmous A, Greenberg BG. Statistical age-period cohort analysis: a review and critique. $f$ Chron Dis 1985;38:811-30.

11 La Vecchia C, Lucchini F, Negri E, Boyle P, Maisonneuve 1989: I, digestive sites. Eur f Cancer 1992;28:132-235

12 World Health Organization. Health for all database. Copenhagen: WHO, 1994.

13 Ledermann S. Alcohol, alcoholism alcoholisation, Vol 2. Paris: Presses Universitaires de France, 1964.

14 Skog OJ. The risk function for liver cirrhosis from lifetime alcohol consumption. $¥$ Studies Alcohol 1984;45:199-208.

15 Wald I, Moskalewicz J. Alcohol policy in a crisis situation. Br f Addiction 1984;79:331-35.

16 Anon. Alcohol policy during extensive socioeconomic change; report on a workshop on alcohol and market economy. Cracow 4-5 June 1993. Copenhagen: WHO Regional Office for Europe, 1994.

17 Levendel L. Az alkoholbetegek egèszsègügyi ellàtàsànak irnyelvei (Major concepts of care for alcoholic patients) Alkohologia 1983;3:11-15.

18 Levendel L. Magyar alkoholellenes akciòprogram (Hungarian alcohol action plan). Szenvedèlybetegsègek 1994;2: 111-25.

19 Andorka R. Az alkoholizmus magyarorszàgi kutatàsa. In: Münnich I, ed. Tanulmànyok a tàrsadalmi beilleszkedsi zavarkkibl. (Research on alcohol in Hungary. In: Münnich I, ed: Studies about difficulties in assimilating society's I, ed: Studies about difficulties in assimilating
values). Budapest: Kossuth Könyvkiadò, 1988.

20 Andorka $R$. Befolyàsoljàk-e az àremelèsek a szeszesital fogyasztàst? (How does increasing the price of alcoholic bevasztast? (How does increasing the price of alcoholic bev-

21 Andorka R. Alkoholizmus ès alkoholpolitika. In: Münnich I Moksony F, eds. Devianciàk Magyarorszàgon (Alcoholism and alcohol policy in Hungary. In: Deviant behaviour in Hungary). Budapest: Közèlet Kiadò, 1994:32-75. 